\title{
Application of mHealth to improve service delivery and health outcomes: Opportunities and challenges
}

\section{Linda Vesel ${ }^{1, a, b}$, David Hipgrave ${ }^{b}$, Justine Dowden ${ }^{c}$ and Wanjiku Kariukid $^{\mathbf{d}}$}

\section{${ }^{a}$ Concern Worldwide US, Innovations for Maternal, Newborn and Child Health b United Nations Children's Fund, Health Section \\ ${ }^{c}$ Columbia University, Mailman School of Public Health \\ ${ }^{\mathrm{d}}$ New York University, Global Institute of Public Health}

\begin{abstract}
The use of mobile technologies for health related activities (mHealth) is a new but rapidly progressing activity with global penetration. However, few programs have been implemented at scale. The objective of this paper is to review the background and evidence on mHealth, particularly with respect to the benefits and challenges of scale-up. A comprehensive review of literature on mHealth, aspects of eHealth and the related regulatory environment was undertaken in August 2014. mHealth innovations vary broadly in purpose, delivery channel and target population. As a result of its broad applicability and geographic reach, the benefits of successfully, safely and widely implemented mHealth are numerous and promising. However, these benefits can only be realized if the associated risks are minimized and the barriers are purposefully overcome. Government stewardship and leadership is crucial in overcoming these barriers and scaling up mHealth.
\end{abstract}

Keywords: mHealth; Technology; Health; Policy; Innovation

\section{Résumé}

L'utilisation des technologies mobiles pour les activités de santé (mSanté) est une activité récente mais en nette et rapide croissance. Cependant peu de programmes ont été mis en place à grande échelle. L'objectif de cette étude est d'examiner le contexte et les évidences dans le domaine de mSanté, particulièrement en ce qui concerne les bénéfices et les défis de son expansion. Une revue de littérature compréhensive sur mSanté, les aspects d'eSanté, et le mécanisme de régulation a été menée en Août 2014. Les innovations de mSanté

\footnotetext{
${ }^{1}$ Corresponding author

Concern Worldwide US, 355 Lexington Avenue, 19th floor; New York NY 10017, USA.

Tel: +1-212-557-8000; Fax: +1-212-557-8004

Email: linda.vesel@concern.net
} 
varient largement par rapport aux objectifs poursuivis, les méthodes de prestation de service et la population-cible. En raison de sa large applicabilité et sa portée géographique, les bénéfices des projets exécutés avec succès et à grande échelle, et garantissant la sécurité, sont nombreux et prometteurs. Cependant, ces bénéfices ne peuvent être réalisés que si les risques associés sont minimisés et les barrières surmontées. Une bonne gouvernance et un rôle-clé des gouvernements sont cruciaux pour surmonter ces barrières et étendre le domaine de mSanté.

Mots clés: mSanté; Technologie; Santé; Politiques; Innovation

\section{Introduction}

\section{Global context}

The use of mobile technologies for health-related activities (mHealth) is a new but rapidly progressing area with exponential growth in its application in the context of burgeoning global access to mobile telephones (Betjeman et al., 2013; Davey and Davey, 20I4; WHO, 20II). According to the International Telecommunication Union, there are now approximately seven billion mobile phone subscriptions in the world, more than three-quarters of which are in the developing world (Davey and Davey, 2014; ITU, 20I4). The rapid increase in mobile phone subscriptions in low and middle income countries (LMICs) is opening up possibilities for mHealth expansion, as $80 \%$ of the 660 million new subscriptions in $201 \mathrm{I}$ came from those regions (ITU, 20I2). In its relatively short history, mHealth has already penetrated a majority of the world. Of 112 countries that completed a $201 \mathrm{I}$ global survey on eHealth by the World Health Organization (WHO), of which one module was on mHealth, $83 \%$ reported at least one mHealth innovation (WHO, 20II). While most documented examples emanate from high-income nations, reports from LMICs are appearing; recent mHealth reviews have been published from
Bangladesh (Ahmed et al., 20I4), India (Davey and Davey, 20/4) and subSaharan Africa (Betjeman et al., 2013). However, despite these favorable conditions and although many mHealth initiatives are being implemented worldwide, most remain at the pilot stage (Kay et al., 20I I).

\section{Innovations and mHealth}

The potential for mHealth to impact global public health is enormous. For example, while declines in maternal and child mortality rates are likely to be insufficient for achievement of Millennium Development Goals 4 and 5 by the end of 2015 (UNICEF, 20I4), innovative solutions and technologies may address major barriers to health service delivery and uptake of essential interventions critical to survival. Such solutions should be purposefully designed and implemented to address inequities in health service access and coverage among underserved and vulnerable populations. The use of mHealth is an innovation that can assist provision of high quality care to large populations, particularly through the sharing of vital information and engagement of beneficiaries. 


\section{mHealth application and key stakeholders}

mHealth innovations vary broadly in purpose, delivery channel and target population, ranging from remote diagnosis support for community health workers (CHWs) to increasing patient treatment compliance and beyond. mHealth can target large populations at once due to its mobility and technological capacity (Free et al., 20I3) and changes the way that information is accessed (WHO, 20II). Many of the reported mHealth interventions targeting patients aim to improve medication adherence, send appointment reminders and treatment follow-up notices via text message, encourage health behavior change, as well as increase education and awareness of health issues and warning signs (Davey et al., 2014; Davey and Davey, 20I4). The health workforce also has much to gain from mHealth, especially in low-resource settings, because mobile technologies can allow providers to circumvent health systems limitations. For example, CHWs in rural areas can use mHealth innovations to collect and disseminate patient data, track vital signs in real-time, undertake disease surveillance and intervention monitoring, receive remote diagnosis support and training, and coordinate with colleagues (Kay et al., 20II; Aranda-Jan et al., 2014). Further applications include emergency medical response, drug supply chain monitoring, transfer of funds, and quality improvement of medical record databases (Aranda-Jan et al., 2014; Davey and Davey, 20I4).

Governments, the private sector and non-profit organizations are expanding their myriad existing mHealth projects.
Indeed, initiatives within the non-profit sector eclipse government-run programs. One report estimated that 352 non-profit and academic institutions are implementing mHealth programs worldwide, compared to 56 government agencies (GSMA mHealth Tracker). Private companies with a stake in community-level activities are also prominent in the field, especially in the telecommunication and pharmaceutical industries. Health call centers, the most common mHealth intervention comprising $59 \%$ of global initiatives, are mostly run by for-profit organizations (WHO, 20I I). Together, these different entities are using their unique positions to offer a broad range of services supported by mobile technology. As mHealth expands, the involvement of the government and institution of policies will be essential in order to mitigate risks and achieve successful scale-up (WHO, 20II).

The overall objective of this paper is to review the background and evidence on mHealth and issues related to its introduction and successful implementation in LMICs, with a focus on maternal, newborn and child health (MNCH). Specific objectives are to: (I) summarize the benefits of its use; and (2) provide an in-depth review of the risks and barriers related to the use of mHealth, with particular focus on the overarching leadership and governance framework that is necessary in order to introduce mHealth applications and expand them to scale.

\section{Methods}

A comprehensive review of the literature on $\mathrm{mHealth}$ and related areas was undertaken in August 2014, in order to understand the underlying enablers 
and barriers to its introduction and scale-up for $\mathrm{MNCH}$ and beyond. Specific attention was paid to the leadership and governance fundamental to its use and potential impact. Formal searches were conducted using the PubMed and Jstor databases and Google Scholar to identify peer-reviewed and grey literature. The search was not restricted by location or year of publication. Information on the benefits and risks of mHealth were derived first from general searches using the key words 'mHealth', 'community health worker', 'health provider', 'client' and 'user.' Within the selected articles, we delved deeper into those that addressed facilitators and barriers more than those detailing implementation processes and logistics. A second search of peer reviewed articles and grey literature included a focus on policy and regulation issues related to mHealth and similar innovations, since this was found to be a major barrier in our first, more general search. A combination of the following keywords were used to search these areas: 'mobile health technology', 'mHealth', 'mobile health policy', 'digital communications', 'phone', 'regulation', 'information and communication technology', 'ICT', 'govern', 'governance' and 'innovation'. All cited references in the identified peerreviewed articles and reports were explored for relevant, additional sources of information. In total, we identified 70 articles of sufficient relevance to support this review. All papers were reviewed by at least two of the authors.

\section{Results}

In view of the existence of other recent overviews, we provide a relatively brief assessment of the numerous and promising benefits of
mHealth as a result of its broad applicability and geographic reach. We then present an extensive review of the potential risks and barriers that, if not purposefully addressed, could prevent successful application and large-scale implementation of mHealth. In doing so, we conclude by focusing specifically on barriers and considerations related to leadership and governance.

\section{Benefits of mHealth}

Harnessing the potential of mobile phones for health can be beneficial to stakeholders across the spectrum-from Ministry of Health officials to rural health workers. Mobile phones can break down gender and social barriers, reduce logistical inefficiencies, and foster the capacity of $\mathrm{CHWs}$ to provide high quality care (Jennings and Gagliardi, 2013; Tomlinson et al., 2009; Chang et al., 20II). While these benefits can all strengthen health systems as a whole, mHealth plays a particularly important and beneficial role in $\mathrm{MNCH}$ and reproductive health (Davey and Davey, 2014; Mechael, 2010). Related initiatives have resulted in increased emergency obstetric care accessibility, stronger communication and information sharing between midwives and health workers, more reliable maternal health data collection and a stronger support system for midwives and women (Speciale and Freytsis, 2013; Chib and Chen, 201I; Mechael et al., 2010). mHealth can support $\mathrm{MNCH}$ programming and policy by allowing health workers to more easily register births and deaths in real time using text messaging. For policymakers and program implementers, increasing the accuracy of mortality and morbidity estimates helps to assess needs and to support 
prevention efforts (Braun et al., 2013; UNICEF, 20II).

In their systematic review, Jennings and Gagliardi (2013) identified several ways in which mHealth can reduce barriers to gender and social equity. The provision of mobile-based health information can facilitate knowledge sharing and communication to both men and women (Aranda-Jan et al., 20l4). A study in Tanzania allowed men to access information about family planning methods through a free and anonymous SMS portal, thus avoiding the obstacles involved in getting men to health facilities for such counseling or relying on their female partners to relay the information directly (L'Engle et al., 2012). Moreover, mHealth initiatives that are easily accessible, such as a hotline, can increase a woman's autonomy in seeking care for her child as she can receive useful advice on the phone without having to depend on her husband to provide money for travel to a health facility if home-based care is possible. In the event that a referral is needed, a woman's desire to seek care would be further substantiated through a formal recommendation by a trained health provider via a mHealth platform. Chib and Chen (20II) note that improving knowledge through mobile devices is itself empowering, because women are better able to make more informed decisions. It is important to note, however, that increased autonomy for women may be viewed unfavorably by men as the primary decision-makers, so mHealth should be implemented in a culturally and context sensitive manner (Jennings, and Gagliardi, 2013; Misraghosh et al., 20I I).

mHealth programs targeting the health workforce have also produced positive outcomes. CHWs often serve rural areas that are hard to reach due to transportation issues. Using mobile phones to address health concerns or follow up with patients remotely benefits the client and the $\mathrm{CHW}$ by saving them both time and the expense of travel (Mahmud et al., 2010). mHealth tools can also increase the capacity of the health workforce, particularly CHWs, not only through lowering logistical hurdles but also through skillbuilding and empowerment. CHWs often have limited training or access to supervision and lack the necessary tools to provide quality services or track patient wellbeing (Braun et al., 20l3). To address this problem, a pilot program in Indonesia gave mobile phones to midwives, midwife coordinators and physicians in an effort to build capacity, increase intra-health worker communication and improve efficiency. Another component of the program involved sending midwives educational SMS messages. Not only did mobile phones allow midwives to remotely access clinical information, collect and track patient data, and facilitate emergency referral and transport, the program also had a psychosocial impact. Midwives reported an enhanced sense of empowerment as well as greater confidence and relationships with the community and other health workers (Jennings an Gagliardi, 2013; Chib and Chen, 20II).

Mobile technology also facilitates increased efficiency through higher quality and more timely data monitoring and reporting techniques (Braun et al., 2013; Mahmud et al., 2010). Data collected this way, compared to paperbased methods, also has been shown to contain fewer errors and gaps (BernabeOrtiz et al., 2008; Braun et al., 2013; Tomlinson et al., 2009;). This 
improvement has policy implications because it allows officials to track health trends in real time and respond more quickly and effectively to emerging problems. Additionally, mobile devices are practical because they are lightweight, cost-effective, easily accessible and multi-functional, thus increasing convenience for health workers (Buehler et al., 20I3).

\section{Risks and barriers of mHealth}

Though the vast application and potential of mHealth is clear, its use and coverage retains many risks and barriers. Risks and obstacles are discussed according to various thematic areas highlighted by Betjeman and colleagues (2013), Leon and colleagues (2012) and the 20II WHO survey. Evidence on barriers is presented in the following categories: financial feasibility; knowledge, research and evidence; infrastructure, access, equity and quality; privacy, security and interoperability; and cultural context. We then focus in greater detail on the overarching theme of leadership and governance.

\section{Financial feasibility}

Empirical data regarding the financial feasibility of mHealth interventions, specifically with regard to operating costs and cost effectiveness, is very limited. This makes it difficult to engage with policymakers to encourage them to prioritize the scale-up of mHealth activities over other evidence-based public health interventions (Chib et al., 2014; Leon et al., 2012). Operational costs of mobile communication, in particular the fees charged to clients by mobile network providers, adversely impact the frequency of user engagement with mHealth services
(Tamrat and Kachnowski, 20I2). Overcoming this barrier involves a detailed analysis of the incentives of various actors, including end users, investors, platform providers and policymakers (Ivatury et al., 2009). One such examination of incentives concluded that smaller mHealth programs incur larger average total costs because there is a limited volume to distribute operational costs from private platform providers. In contrast, one-way SMS-based activities incur less prohibitive maintenance costs, regardless of the program's size, because they primarily require an initial investment with a relatively low and stable operational cost (Vital Wave Consulting, 2009; Tamrat and Kachnowski, 20I2).

Additionally, mHealth interventions relying primarily on donor funding encounter the issue of long-term sustainability. One consideration would be donor exit strategies involving government succession (Ogunmefun et al., 2010). An example of such an exit strategy is Thailand's Better Border Healthcare Programme in which the government covers the operational costs of sending text messages to obstetrical patients to alleviate the financial costs for end users (Seebregts et al., 2009; Tamrat and Kachnowski, 20I2). Another solution in countries where governments are key stakeholders in mHealth programs is gradual adoption of toll-free services for health related mobile communication as demonstrated by mHealth program expansion and integration in Rwanda (Mechael, 2008; Tamrat and Kachnowski, 20I2). 
Knowledge, research and evidence

Lack of knowledge and evidence on the impact of at-scale mHealth interventions on key health indicators is a major obstacle to improving mHealth coverage. This includes a lack of standardization of mHealth study designs. To facilitate randomized control studies and standardized, replicable study designs, WHO has recommended changing the research focus of mHealth interventions from usability to a health outcomes-based approach (WHO, 20 I I; Betjeman et al., 20l3). Literature on the effectiveness (including cost effectiveness) of mHealth in LMICs, specifically for behavior change, is limited (Chib et al., 20l4; Betjeman et al., 20l3). There is also a paucity of literature discussing failed mHealth interventions or studies elucidating the process of technology adoption. Collaboration between information communication technology (ICT) innovators, social scientists and public health practitioners is vital, particularly in establishing standardized theoretical frameworks, evaluation methods and guidelines for measurement (Chib et al., 2014).

Although the opportunities for $\mathrm{mHealth}$ are profound, there is a plethora of designs and an absence of related evaluation or evaluation frameworks (Kahn et al., 2010; Betjeman et al., 20l3). In Bangladesh, this problem was particularly noted for the activities conducted by the private sector, which comprised the majority. Absence of evaluations of mHealth initiatives globally has been a stumbling block, along with the speed at which the related technology is evolving, for development of government regulatory policy (WHO, 20II). Put simply, the science of mHealth is evolving much faster than societies' or governments' ability to adapt their policies and practices to keep up. For wider uptake of mHealth, more iterative monitoring and evaluation strategy and engagement of the government is required; governments need evidence that is properly contextualized.

Infrastructure, access, equity and quality

Another significant hurdle for mHealth programs is poor infrastructure (Tamrat and Kachnowski, 20I2). One explanation for the feasibility mismatch between mHealth program requirements and the reality of infrastructure limitations in target countries may be that most mHealth research is conducted in high-income countries with advanced infrastructure not yet as widely available in LMICs. This is particularly true regarding telecommunications infrastructure that can be a barrier in mHealth applications entailing broadband internet access, the use of smart phones and remote access to electronic medical records (Betjeman et al., 2013). Moreover, poor coverage of and accessibility to mHealth interventions, particularly among vulnerable populations, is often a result of low ownership of mobile phones, sometimes despite high network coverage. A study in Kenya found that nearly $40 \%$ of sampled patients did not own a personal mobile phone, with disparities in phone ownership vis-à-vis gender, age, education, literacy, urbanization and poverty (Zurovac et al., 2013).

Issues of equitable coverage and access are likely to be resolved with the current rapid expansion of mobile phone infrastructure and increased mobile 
phone penetration in low-income countries (Zurovac et al., 20I3). Indeed, there is overwhelming expectation that the rapid expansion of market-driven telecommunication infrastructure in LMICs could soon overcome current feasibility challenges; current projections suggest that operational costs will decline and infrastructure will improve rapidly in the coming years, indicated by increasing mobile penetration even in remote areas of low income countries (Betjeman et al., 2013). mHealth increases accessibility to health services, particularly in isolated rural communities. Its utilization by $\mathrm{CHWs}$ encourages decentralization of the health system which helps to overcome multiple barriers to health seeking behaviors by rural populations including accessibility to transport, transport costs and time barriers; thus, ultimately health care worker impact and efficiency is maximized (Braun et al., 2013; Mahmud et al., 20।0).

The potential for mHealth programs to improve quality of care may be compromised by a lack of investment in infrastructure, and the absence of sustainable financing and technological training (Braun et al., 2013; Chib et al., 2008). Current evidence on mHealth programs does not adequately address their impact on quality and efficiency in terms of improving service delivery processes, strengthening health systems and improving health outcomes (Leon et al., 2012).

\section{Privacy, security and interoperability}

A universal concern of all mHealth activities is that of data protection, privacy and security. Many LMICs recognize the right to privacy but have legal frameworks that lack an explicit data protection act (Fraser and Blaya, 2013). Currently, most small-scale mHealth activities in LMICs have varying security measures such as firewalls and tiered password access control codes that allow for different levels of access for CHWs and managers (Leon et al., 2012; Betjeman et al., 2013). Ultimately, however, information security can only be adequately addressed with a large enough industry buy-in to facilitate standardization and policy implementation (Betjeman et al., 2013).

Another major technological challenge is the complexity of ensuring interoperability and integration of information systems. Interoperability is the functional exchange of data between information systems, which ensures that there is unhindered and efficient communication across platforms as well as integration with existing work practices (Leon et al., 20I2). Examples include data transmission from $\mathrm{CHWs}$ to centralized health systems, and syncing community and central electronic patient management records in a manner that facilitates the monitoring of bi-directional referral, follow-up care and medical prescriptions (Leon et al., 2012). The literature inextricably links interoperability with the concerns of privacy and security, and suggests that these technological challenges as a whole could be resolved with standardized data security policies such as data encryption or open architecture, which would allow sharing across platforms and would support innovation (Tate et al., 20/3). Notably, interoperability, while in the best interest of end users, may not be an objective of some stakeholders, especially commercial entities, for whom information exchange might limit 
competitive advantage (Tate et al., 20I3).

\section{Socio-cultural context}

Socio-cultural barriers are a common challenge faced in the scale-up of many mHealth programs. Age is a major predictor of the adoption of technology, with older people less likely to adopt new technology (Czaja et al., 2006; Charness and Boot, 2010) as a result of their cognitive abilities, low awareness of the technology's benefit, perceived competence and anxiety related to its use; perceptions of technology also vary by age (Czaja et al., 2006; Charness and Boot, 20I0). Additionally, education, socioeconomic status, and local perception and attitudes toward technology determine its adoption (Czaja et al., 2006).

A first step to resolving these sociocultural barriers is adapting mHealth programs to the local context, including language translation, and addressing cultural perception and nuances (Tamrat and Kachnowski, 20I2). Specific training for older or minority populations on the benefits of technology use and counseling on self-efficacy and anxiety for such groups can reduce these barriers and disparities (Czaja et al., 2006; Mitzner et al., 2010). An example of contextualizing mHealth is China's integration of ICT within the rural health care system using informal social networks - guanxi - to facilitate health information exchanges mediated by technology. It has been postulated that this merger between ICT and the Confucian tradition guanxi lends a sense of security and trust to mHealth information exchange among end users (Chib, 2013).

\section{Leadership and governance}

\section{Policy and oversight}

Careful monitoring, evaluation and regulation are needed to overcome and address the various risks and barriers to the uptake and scale-up of mHealth interventions. Higher-level mechanisms and commitments from key stakeholders are needed to drive and control the effective, sustainable and impactful use of mHealth. Most mHealth initiatives, applications and strategies lack backing by appropriate government policies, regulations and oversight. This may create risks for both the users and providers of this technology and impact the rate of its introduction, scalability from pilot studies to integrated national health initiatives, utility and the overall cost-benefit balance (Betjeman et al., 2013).

The regulation and evaluation of mHealth initiatives is an example of the broader problem of regulating rapidly developing technologies, as previously acknowledged for biotechnology (Barton, 20I2). It is especially problematic in LMICs characterized by weak governance. More broadly, mHealth is a perfect example of innovation that requires governments to develop related policies and guidelines despite the fact that the majority of the engagement is done by the private sector. The objectives of innovation policy are often macroeconomic, such as financial or productivity growth, increased employment and competitiveness. However, innovations in mHealth have the most immediate impact on individuals. Moreover, the related technological innovations are increasingly funded not by public grants but driven by commercial incentives, again underscoring concerns about 
developing the right balance between incentives and boundaries for related research and development (Chaminade and Esquist, 2010).

\section{Regulatory frameworks}

Technology and policy in areas such as mHealth is no longer simply a national issue, as the very nature of technology is that it crosses national borders and must take into account regional or transnational developments and regulations. International agencies have defined the qualities that should apply to putative regulatory frameworks for eHealth, of which mHealth is a sub-set (The Rockefeller Foundation, 20I0). While developed countries are increasingly adopting these regulatory frameworks on eHealth, few LMICs have moved to adapt or develop them (Betjeman et al., 20I3). In South Africa, notwithstanding a supportive policy environment, implementation of mHealth without a supportive legal framework is creating risks for both health facilities and CHWs (Leon et al., 20I2; Holeni, 20I3).

Developers of mHealth solutions also have a stake in its regulation. For example, the United States Food and Drug Administration (FDA) has issued guidance concerning the regulation of mobile medical applications (Blumenfeld and Garvin, 2013). While the guidance focuses appropriately on patient safety, industry concerns have emerged that excessive regulation may limit innovation and discovery, and impact the evolving nature of mHealth and health service delivery (Barton, 2012). In fact, the guidance suggests that the FDA is keeping a relatively open-mind and has taken a logical, risk-based approach to regulation of mHealth applications.
However, one might expect such an approach to evolve, particularly if an mHealth approach currently not subject to regulation causes patient harm in the future.

Country example of successful scale-up resulting from government leadership

Rwanda is one of the most successful examples of developing and sustaining mHealth at scale with government commitment, integration of $\mathrm{mHealth}$ within the existing health system, and collaboration across sectors. Rwanda's mHealth system--TRACnet--is the longest continuously operating national mHealth system in Africa (Nyemazi, 20II). The TRACnet system is used to track HIV/AIDS, malaria, tuberculosis and other diseases (Korvald, 2013). Data collected by TRACnet is used for a variety of purposes including monitoring program expansion and progress, driving performance-based incentive payments to health centres, delivering lab results to facilitate early infant diagnosis, monitoring pharmaceutical supplies, and providing donor reporting (Nyemazi, 20II). The system includes a national interoperable electronic health system, rollout of electronic management records and data input from CHWs through solar-powered mobile phones (Gerber et al., 2010; Nash et al., 2009).

\section{Discussion}

The synthesis of evidence presented above highlights the opportunity that mHealth presents to improve the quality, equity, coverage and timing of care. It also emphasizes the need to consciously address a large spectrum of barriers in the design, implementation and scale-up of mHealth interventions. Finally, the literature highlights the need 
for ownership and leadership from the government in order to scale-up and sustain mHealth strategies and to ensure that all those involved reap the benefits.

The literature suggests that a mHealth policy or regulatory framework would best incorporate the following principles: alignment with national health objectives; alignment with or synergy between various existing initiatives; coordination between government and private sector agencies to establish and enforce guidelines on the content and technological design of services; and exchange of data and assurances of infrastructure including network coverage. It would also engage local partners to develop messages that are in the local language and culturally appropriate in order to ensure equitable access and participation, and standardize information security. A mHealth policy should also address its integration with existing platforms for both information dissemination and receipt, the responsibility of individuals (providers and clients) to act on the information disseminated or received, and underwrite a commitment to an improved technological environment.

The global uptake and demand for new information technology has created an ideal environment for harnessing mHealth and an opportunity to tackle health issues in innovative ways to overcome barriers that other interventions have not been able to. For example, global initiatives such as the recently launched Every Newborn: an action plan to end preventable deaths by WHO and UNICEF (20I4) promotes the use of ICT to improve quality of care, monitoring, communication and data sharing. Every Newborn also highlights the utility of mHealth in harnessing the power of parents, families and communities to promote quality newborn care and survival and to overcome barriers of access to care, particularly for the remote and underserved (WHO and UNICEF, 20I4).

However, mHealth scale-up is challenged by the need to prove absence of risk across multiple sites and in multiple areas of use, with multiple different actors having different needs, objectives and standards. Balancing the interests of individuals, communities, governments and the private sector is difficult and requires a great deal of coordination and commitment.

\section{Conclusion}

Successful scale-up of mHealth relies on a collaborative approach harnessing the strengths of all partners, including the private sector. Governments must take ownership to make mHealth initiatives sustainable, scalable and beneficial to all users and beneficiaries, while retaining privacy and safety. Progress is dependent on the attainment of a balance between the need for caution and the desire. Despite the uncertainties and investments needed, the benefits are promising and the time to act is now.

\section{Acknowledgements}

This paper was written to anchor some of the themes of innovation and mobile health technologies utilized in the projects piloted by Concern Worldwide US's Innovations for Maternal, Newborn \& Child Health initiative. Innovations aims to accelerate the discovery and testing of creative solutions to understand and overcome barriers that prevent essential health services from reaching women and children in Ghana, India, Kenya, 
Malawi and Sierra Leone. This initiative is funded through a multi-year grant from the Bill \& Melinda Gates Foundation. We would like to thank Dr. Jean Christophe Fotso for reviewing the manuscript and making valuable suggestions regarding content and structure. We are also grateful to the anonymous reviewers.

\section{Authors' contributions}

LV, DH, JD and WK all conducted literature reviews and summarized findings. LV led the drafting of the manuscript with help from all authors. All authors read and commented on multiple drafts of the manuscript and approved the final version.

\section{References}

Ahmed, T., Lucas, H., Khan, A.S., Islam, R., Bhuiya, A., et al. 20l4. "eHealth and mHealth initiatives in Bangladesh: a scoping study." BMC Health Serv Res, 14: 260.

Aranda-Jan, C.B., Mohutsiwa-Dibe, N. \& Loukanova, S. 2014. "Systematic review on what works, what does not work and why of implementation of mobile health (mHealth) projects in Africa." BMC Public Health, 14(I), I-28. doi:I0.I I86/I47|-2458-I4188.

Barton, A.J. 2012. "The regulation of mobile health applications." BMC Medicine, 10: 46.

Bernabe-Ortiz, A., Curioso, W.H., Gonzales, M.A., Evangelista, W., Castagnetto, J.M., et al. 2008. "Handheld computers for selfadministered sensitive data collection: a comparative study in Peru." BMC Med Inform Decis Mak, 8: II. doi: I0. I I86/I472-6947-8-II.
Betjeman, T.J., Soghoian, S.E., and Foran, M.P. 2013. "mHealth in subSaharan Africa." International Journal of Telemedicine and Applications, 6.

Blumenfeld, B. \& Garvin, W. 20I3. "An update on mhealth regulation in the United States." Journal of Mobile Technology in Medicine, 2 (3): I-3.

Braun, R., Catalani, C., Wimbush, J. \& Israelski, D. 20I3. "Community health workers and mobile technology: A systematic review of the literature." PLoS One, 8(6). doi:http://dx.doi.org//0.137//journal. pone. 0065772 .

Buehler, B., Ruggiero, R. \& Mehta, K. 2013. "Empowering Community Health Workers with Technology Solutions." IEEE Technology and Society Magazine, 32(I), 44-52. doi:I0.I I09/MTS.2013.224I83I.

Chaminade, C. \& Esquist, C. 2010. Rationales for Public Policy Intervention in the Innovation Process: Systems of Innovation Approach. In: Smits R, Kuhlmann S, Shapira $P$, editors. The Theory and Practice of Innovation Policy: An International Research Handbook. Cheltenham (UK): Edward Elgar.

Chang, L. W., Kagaayi, J., Arem, H., Nakigozi, G., Ssempijja, V., Serwadda, D., et al. 20II. "Impact of a mHealth Intervention for Peer Health Workers on AIDS Care in Rural Uganda: A Mixed Methods Evaluation of a Cluster-Randomized Trial." AIDS and Behavior, I5(8), |776-|784. doi: |0. 1007/s |046|-0| |9995-x.

Charness, N, \& Boot, WR. 2009. Aging and information technology use. Current Directions in Psychosocial Science, 18(5): 253-258. 
Chib, A. \& Chen, V.H. 20II. "Midwives with mobiles: A dialectical perspective on gender arising from technology introduction in rural Indonesia." New Media \& Society, I3(3), 486-50I. doi:http://dx.doi.org//0.1 I77//46/44 4810393902

Chib, A., Lwin, M.O., Ang, J., Lin, H. \& Santoso, F. 2008. "Midwives and mobiles: using ICTs to improve healthcare in Aceh Besar, Indonesia I." Asian Journal of Communication, I8(4), 348-364.

Chib, A., Phuong, T.K., Si, C.W. \& Hway, N.S. 2013. "Enabling informal digital guanxi for rural doctors in Shaanxi, China." Chinese Journal of Communication, 6(I), 62-80.

Chib, A., van Velthoven, M.H. \& Car, J. 2014. "mHealth adoption in lowresource environments: A review of the use of mobile healthcare in developing countries." Journal of Health Communication (ahead-ofprint), I-53.

Czaja, S.J. Charness, N., Fisk, A.D., Hertzog, C., Nair, S.N., Rogers, W.A. \& Sharit, J. 2006. "Factors predicting the use of technology: findings from the Center for Research and Education on Aging and Technology Enhancement (CREATE)." Psychol Aging, 2I(2): 333-352.

Davey, S. \& Davey, A. 2014. "Mobilehealth technology: Can it Strengthen and improve public health systems of other developing countries as per Indian strategies? A systematic review of the literature." International Journal of Medicine and Public Health, 4: 4045.

Davey, S., Davey, A. \& Singh, J. 2014. "Mobile-health approach: A critical look on its capacity to augment health system of developing countries." Indian Journal of Community Medicine, 39(3), 178-182.

Fraser, H.S. \& Blaya, J. 2010. "Implementing medical information systems in developing countries, what works and what doesn't" In AMIA Annual Symposium Proceedings:232. American Medical Informatics Association.

Free, C., Phillips, G., Watson, L., Galli, L., Felix, L., Edwards, P., Patel, V. \& Haines, A. 2013. "The effectiveness of mobile-health technologies to improve health care service delivery processes: a systematic review and meta-analysis." PLoS Medicine, IO(I): I-26.

Gerber, T., Olazabal, V., Brown, K. \& Pablos-Mendez, A. 20I0. "An agenda for action on global e-health." Health Affairs, 29(2): 233-236.

GSMA mHealth Tracker - Mobile World Live.

http://www.mobileworldlive.com/mh ealth-tracker.

Holeni, K. 20I3. Lessons for policy and regulation from mobile applications in public health: The Case of Community Health Work in Daspoort, South Africa (Masters thesis document). Johannesburg: University of the Witwatersrand.

ITU: Key statistical highlights: ITU data release June 2012. Geneva: International Telecommunications Union; 2012.

ITU: The World In 2014: ICT Facts And Figures. Geneva: International Telecommunications Union; 2014. Ivatury, G., Moore, J. \& Bloch, A. 2009. "A doctor in your pocket: health hotlines in developing countries." Innovations, 4(I): II9I53.

Jennings, L. \& Gagliardi, L. 2013. "Influence of mhealth interventions 
on gender relations in developing countries: A systematic literature review." International Journal for Equity in Health, 12. doi:http://dx.doi.org/10.1 186/I475-9276-12-85.

Kahn, J.G., Yang, J.S. \& Kahn, J.S. 2010. '"Mobile' health needs and opportunities in developing countries." Health Affairs, 29: 252258.

Kay, M, Santos, J, Takane, M. $201 \mathrm{I}$. mHealth: New horizons for health through mobile technologies. Global observatory for eHealth series. Volume 3. Geneva: World Health Organization.

Korvald, M. 2013. Integrating mobile and web health infrastructures in low resource contexts. University of Oslo.

L'Engle, K.L., Vahdat, H.L., Ndakidemi, E., Lasway, C. \& Zan, T. 2012. "Evaluating feasibility, reach and potential impact of a text message family planning information service in Tanzania." Contraception, 87(2): 25I256.

Leon, N., Schneider, H. \& Daviaud, E. 2012. "Applying a framework for assessing the health system challenges to scaling up mHealth in South Africa." BMC Medical Informatics and Decision Making, I2(I): 123.

Mahmud, N., Rodriguez, J. \& Nesbit, J. 2010. "A text message-based intervention to bridge the healthcare communication gap in the rural developing world." Technol Health Care, 18(2): 137-44

Mechael, P. N. 2008. mHealth in the Millennium Village Project. New York: Earth Institute.
Mechael, P.N. 2010. "Case study from Egypt: mobile phones for mother and child care." 14d: The first monthly magazine on ICT4D. http://unpan I.un.org/intradoc/groups/ public/documents/unpan/unpan03736 5.pdf.

Mechael, P.N., Batavia, H., Kaonga, N., Searle, S., Kwan, A., Goldberger, A., $\mathrm{Fu}$, L. \& Ossman, J. 20I0. Barriers and Gaps Affecting mHealth in Low and Middle Income Countries: Policy White Paper. Columbia University. Center for Global Health and Economic Development. New York: Earth Institute.

Misraghosh, A., Sirohi, M.S., Crampsie, S. \& Burchell, J. 20II. Uninor: Empowering women through an innovative mobile distribution model. http://www.gsma.com/mobilefordeve lopment/wpcontent/uploads/2013/0I/GSMA_mW omen Uninor Case StudyNovember_20II_FINAL.pdf.

Mitzner, T.L., Boron, J.B., Fausset, C.B., Adams, A.E., Charness, N., Czaja, S.J., Dijkstra, K., Fisk, A.D., Rogers W.A. \& Sharit, J. 20I0. "Older adults talk technology: technology usage and attitudes." Comput Human Behav, 26(6): |7| $|0-| 72 \mid$.

Nash, D., Elul, B., Rabkin, M., Tun, M., Saito, S., Becker, M. \& NuwagabaBiribonwoha, H. 2009. "Strategies for more effective monitoring and evaluation systems in HIV programmatic scale-up in resourcelimited settings: implications for health systems strengthening." Journal of Acquired Immune Deficiency Syndromes, 52, S58-S62.

Nyemazi, J.P. 20II. "P5-S4. 01 TRACnet: sustaining mHealth at scale in Rwanda." Sexually 
Transmitted Infections, 87(Suppl I),

Ogunmefun, C., Mothibe, N. \& Friedman, I. 20I0. Electronic Community Care Giver (CCG) Study: A summative evaluation of the implementation of an Electronic Monitoring and Evaluation Solution for CCG programmes. Durban: Health Systems Trust.

Seebregts, C.J., Zwarenstein, M., Mathews, C., Fairall, L., Flisher, A.J., Seebregts, C., et al. 2009. "Handheld computers for survey and trial data collection in resource-poor settings: Development and evaluation of PDACT, a Palm ${ }^{\mathrm{TM}}$ Pilot interviewing system." International Journal of Medical Informatics, 78(II): 72I-73I.

Speciale, A.M. \& Freytsis, M. 2013. "mHealth for Midwives: A Call to Action." Journal of Midwifery \& Women's Health, 58(I): 76-82. doi: I0.III I/j.I542-20I I.20I2.00243.

Tamrat, T. \& Kachnowski, S. 2012. "Special Delivery: An Analysis of mHealth in Maternal and Newborn Health Programs and Their Outcomes Around the World." Maternal and Child Health Journal, 16(5):

1092-1101.

doi: I0.1007/s 10995-0 I I-0836-3.

Tate, E.B., Spruijt-Metz, D., O'Reilly, G., Jordan-Marsh, M., Gotsis, M., Pentz, M.A. \& Dunton, G.F. 2013. "mHealth approaches to child obesity prevention: successes, unique challenges, and next directions." Translational behavioral medicine, 3(4): 406-4I5.

The Rockefeller Foundation. 2010. From Silos to Systems: An Overview of eHealth's Transformative Power. New York: The Rockefeller Foundation.

Tomlinson, M., Solomon, W., Singh, Y., Doherty, T., Chopra, M., et al. 2009.
"The use of mobile phones as a data collection tool: a report from a household survey in South Africa." BMC Med Inform Decis Mak, 9: 51 . doi: 10.1 I86/I472-6947-9-5I.

UNICEF. 2014. Levels and Trends in Child Mortality. Report 2014: Estimates Developed by the UN Inter-agency Group for Child Mortality

Estimation. http://www.unicef.org/media/files/Le vels_and_Trends_in_Child_Mortality 2014.pdf.

UNICEF. 20II. Uganda Telecom Limited and UNICEF team up to tackle Uganda's birth registration problem. UNICEF Uganda Media Centre.

http://www.unicef.org/uganda/6007_965 2.html.

UNICEF \& WHO. 20I4. Countdown to 2015. Fulfilling the health agenda for women and children. The 2014 Report.

http://www.countdown2015mnch.or g/documents/20I4Report/Countdow n_to_2015-

Fulfilling\%20the\%20Health_Agenda_ for_Women_and_Children-

The 2014 Report-

Conference_Draft.pdf.

Vital Wave Consulting. 2009. mHealth for development: the opportunity of mobile technology for healthcare in the developing world. Washington DC and Berkshire, UK.

WHO. 20I I. mHealth: new horizons for health through mobile technologies: second global survey on eHealth. Geneva: World Health Organization. http://www.who.int/goe/publications/ goe_mhealth_web.pdf.

WHO \& UNICEF. 20I4. Every Newborn: an action plan to end preventable deaths. Geneva: World Health

Organization. 
African Population Studies Special Edition, 2015

http://www.everynewborn.org/Docu ments/Every_Newborn_Action_PlanENGLISH_updated_July20I4.pdf.

Zurovac, D., Otieno, G., Kigen, S., Mbithi, A.M., Muturi, A., Snow, R.W.
\& Nyandiqisi, A. 2013. "Ownership and use of mobile phones among health workers, caregivers of sick children and adult patients in Kenya: cross-sectional national survey." Global Health, 9: 20. 